\title{
Optimization of total phenolic extraction of Chromolaena odorata leaf for antifungal activity against plant pathogens
}

\author{
Vinh H. D. Nguyen ${ }^{1}$, Anh V. T. Nguyen ${ }^{2}$, Toan Q. Truong ${ }^{2}$, \\ Ly. P. T. Trinh ${ }^{2}$, \& Biet V. Huynh ${ }^{2 *}$ \\ ${ }^{1}$ Department of Biotechnology, Nong Lam University, Ho Chi Minh City, Vietnam \\ ${ }^{2}$ Research Institute for Biotechnology and Environment, Ho Chi Minh City, Vietnam
}

ARTICLE INFO
Research Paper
Received: October 01, 2019
Revised: November 04, 2019
Accepted: December 05, 2019
Keywords
Antifungal
Chromolaena odorata
Microwave-assisted extraction
Phenolics
Response surface methodology

\section{${ }^{*}$ Corresponding author}

Huynh Van Biet

Email: hvbiet@hcmuaf.edu.vn

\begin{abstract}
Phenolic compounds are secondary metabolites mainly responsible for different pharmacological activities of the plant extracts. In this study, microwave-assisted extraction (MAE) variables were optimized for the extraction of the phenolic compounds from Chromolaena odorata ( $C$. odorata) by using a central composite design (CCD) of response surface methodology (RSM). The optimized conditions were at $62^{\circ} \mathrm{C}$ for $3 \mathrm{~min}$ with solvent to feed ratio of $14: 1(\mathrm{~mL} / \mathrm{g})$ and ethanol concentration of $50 \%(\mathrm{v} / \mathrm{v})$. The highest yield of total phenolic compounds was 75.76 mgGAE/g. Ethanol extract clearly showed antifungal activity through antifungal index. The antifungal effect Phytophthora capsici, Fusarium oxysporum and Colletotrichum siamese were $79.07 \%, 78.66 \%$ and $78.42 \%$, in $0.5 \%$ of ethanol extract, respectively.
\end{abstract}

Cited as: Nguyen, V. H. D., Nguyen, A. V. T., Truong, T. Q., Trinh, L. P. T., \& Huynh, B. V. (2019). Optimization of total phenolic extraction of Chromolaena odorata leaf for antifungal activity against plant pathogens. The Journal of Agriculture and Development 18(6), 38-48.

\section{Introduction}

Chromolaena odorata (C. odorata) belongs to the Asteraceae family, its chemical composition contains many flavonoid compounds including flavones, flavonols, flavanons and chalcones. Flavonoids are the decisive ingredients for the biological activities which were proved to have strong antioxidant activity, combined with anti-inflammatory effects have increased effectiveness in wounds. $C$. odorata leaves also contain a high amount of essen- tial oils. The main ingredients of $C$. odorata essential oil include: $\alpha$-pinene, $\beta$-pinene, D-limonene, $\beta$-ocimene, Caryophyllene, Pregeijerene, Germacrene-D, $\delta$-cadinene, $\alpha$-copaene, Caryophyllene oxide, $\delta$-humulene. . (Moses et al., 2010). In addition, C. odorata also contains long-chain or cyclic polyunsaturated fatty acids. Phenolic compounds were metabolic products of arachidonic acid that were considered defense weapons against plant pathogens. Adeyemo (2018) reported that ethanolic extract of $C$. odorata showed the highest antifungal effects against 
Phytophthora megakarya, followed by cold-water extracts. Zones of clearance range were from $15.00 \mathrm{~mm}$ to $32.00 \mathrm{~mm}$ for ethanolic extraction while cold water extract was from $5.00 \mathrm{~mm}$ to $30.00 \mathrm{~mm}$ at concentration from $1 \%$ to $5 \%$.

Microwave-assisted extraction has been employed to recover phenolic compounds from $C$. odorata leaves. The MAE is a novel, unconventional extraction method that is more efficient in recovering quality yields with reduced extraction time and less solvent (Moses et al., 2010). The MAE is affected by different factors including microwave power, temperature, irradiation time, solvent concentration, and solvent to feed ratio. To optimize these factors, response surface methodology (RSM) was used as a statistical method to generate the predictive mathematical model that takes into account possible interactions between the factors under consideration (Khuri \& Mukhopadhyay, 2010). A central composite design (CCD) had been employed herein because it is one of the most efficient types of RSM and is useful in avoiding experimental processes under extreme conditions, which can result in unsatisfactory results.

Although $C$. odorata has been used as a medicine in Vietnam, there are not many studies on optimizing the process of obtaining phenolicrich extract from $C$. odorata, especially biodynamic agriculture in general, biopesticides for plant pathogenic fungi in particular. Dwijendra (2014) mentioned that the use of chemical pesticides have negative impacts on animals, humans, even the whole ecosystem. Therefore, one of the proposed solutions is to use compounds from plants, especially phenolic. These compounds are not only effective in controlling diseases in plants, but also sustainable with the ecosystem. According to Kumlachew et al. (2014), using Ruta chalepensis extract to inhibit the growth of anthracnose Colletotrichum gloeosporioides on mango. The extract reduced the development of the disease to less than $36 \%$, while for the control the level of damage was $93.4 \%$. Therefore, this study investigated the optimization of phenolic compounds from $C$. odorata leaves and analyzed inhibition of three plant pathogenic fungi strains. MAE is used to extract phenolics compounds from $C$. odorata. Extraction conditions including temperatures, times, ethanol concentrations and solvent to feed ratio were optimized using RSM at CCD. Then, the antifungal activity of plant extract against $P$. capsici, $F$. oxysporum and $C$. siamense was examined.

\section{Materials and Methods}

\subsection{Plant materials, chemicals, and reagents}

Fresh C. odorata was collected at the Research Institute for Biotechnology and Environment (RIBE), Nong Lam University Ho Chi Minh City. The leaves were washed with tap water, dried at $40^{\circ} \mathrm{C}$ for 3 days, pulverized to powder form, and screened to a particle size of $0.1 \mathrm{~mm}$. The powdered sample was stored in a dark container at $\left(25^{\circ} \mathrm{C} \pm 2\right)$. The moisture content of the plant sample before extraction was lower than $12 \%$ water per dry sample.

Fungal strains including P. capsici, F. oxysporum, C. siamense were provided by the Research Institute of Biotechnology and Environment, Nong Lam University, Ho Chi Minh City.

Ethanol, Folin-Ciocalteu reagent, gallic acid, and sodium carbonate were purchased from Sigma Aldrich.

\subsection{Phytochemical screening}

\subsubsection{Alkaloids}

The presence of alkaloids in the ethanolic extract was examined by Dragendroff's test. About $1 \mathrm{~mL}$ of extract was taken and added 3-5 drops of Dragendorff's. Dragendorff's reagent was prepared by $1 \mathrm{~mL}$ mixing solution- 1 containing 0.85 $\mathrm{g}$ of bismuth (III) nitrate and $10 \mathrm{~mL}$ acid acetic in $40 \mathrm{~mL}$ of water, $1 \mathrm{~mL}$ solution- 2 containing 8 g potassium iodide in $20 \mathrm{~mL}$ water to a solution of glacial acetic acid $(4 \mathrm{~mL})$ in deionization water $(14 \mathrm{~mL})$. If orange-red precipitate is formed after 3 min, indicating the presence of alkaloids in the crude extract.

\subsubsection{Saponins}

The presence of saponins in the ethanolic extract was examined by Froth test. About $0.5 \mathrm{mg}$ of the extract was mixed with $5 \mathrm{~mL}$ of distilled water in a test tube and vigorously shaken for 2 min. Foam which persisted for 30 min and doesn't disappear upon warming indicates the presence of saponins in the extract. 


\subsubsection{Flavonoids}

The presence of flavonoids in the ethanolic extract was examined by Shinoda Test. About 10 mg of extract was added to pinch of magnesium and 3 drops of concentrated hydrochloric acid was added. Formation of orange-pink colour indicates the presence of flavonoids.

\subsubsection{Phenolic compounds}

The presence of phenolic compounds in the ethanolic extract was examined by lead acetate test. About $10 \mathrm{mg}$ of extract was taken and 0.5 $\mathrm{mL}$ of $1 \%$ lead acetate solution was added and the formation of precipitate indicates the presence of tannins and phenolic compounds.

\subsubsection{Tannins}

The presence of tannins the ethanolic extract was examined by ferric chloride test. About 0.5 mg of the extract, ferric chloride $5 \%$ a solution was added. Formation of dark blue precipitate indicates the presence of tannins.

\subsection{MAE of $C$. odorata leaves}

In all the above experiments, whether the dried C. odorata leaves have uniform size, were sifted through the $\phi 1 \mathrm{~mm}$ sieve. The weight of material for several extracts was $1 \mathrm{~g}$. The extraction was conducted in a microwave-assisted separator (QLABPro Closed Vessel Microwave Digestion) at different temperatures, times, ethanol concentration and solvent to feed ratio. The filtrate was obtained after centrifugation at $25^{\circ} \mathrm{C}$, for $15 \mathrm{~min}$ (Hermle). Then used for determination of phenolic contents.

\subsection{Determination total phenolic compounds}

Total phenolic compounds (TPC) was determined by the method of Alara et al (2019a) with minor modifications. $30 \mu \mathrm{L}$ of C.odorata extract was mixed with $100 \mu \mathrm{L}$ of Folin-Ciocalteu reagent and $3000 \mu \mathrm{L}$ of deionization water for $5 \mathrm{~min}$, then $300 \mu \mathrm{L}$ of $20 \% \mathrm{Na}_{2} \mathrm{CO}_{3}$ was added to the mixture, filled up to $5 \mathrm{~mL}$. The reaction mixture was kept in a dark room for $120 \mathrm{~min}$ and the absorbance was measured at $735 \mathrm{~nm}$ using a UV/Vis spectrophotometer (Agilent, California). Gallic acid was used as a standard in the determination of
TPC from $C$. odorata leaves (gallic acid equivalents; GAE). The concentration of $C$. odorata leaf extract was calculated in relation to the gallic acid standard curve. Then, TPC was calculated by Eq. (1). The analysis was repeated three times and the results were expressed as mean \pm standard deviation.

$$
\mathrm{TPC}=\frac{\mathrm{A}}{\text { Weight of dried sample used }(\mathrm{g})}
$$

with:

A: Concentration $(\mathrm{mg} / \mathrm{mL}) \times$ volum of solvent used $(\mathrm{mL})$

\subsection{Experimental design and statistical anal- ysis}

Optimization of total phenolic content was carried out using a CCD of RSM. Experimental design includes five levels of 4 independents variables: irradiation time $(2-4 \mathrm{~min})$, extraction temperature $\left(50-70^{\circ} \mathrm{C}\right)$, solvent to feed ratio $(8: 1-14: 1 \mathrm{~mL} / \mathrm{g})$, ethanol concentration (40 $60 \% \mathrm{v} / \mathrm{v}$ ) was designed with Minitab 16.1 Statistical Software ${ }^{\circledR}$ for a total of 31 runs. In exploration studies, the marginal values of the extraction factors were determined as shown in Table 1.

A total of 16 experiments at 2 levels (upper and lower), 8 star experiments and 7 center experiments were carried out. Each experiment was conducted three times and average results were obtained. Experimental data were analyzed by MiniTab 16. The mathematical model of the influence of independent variables on the dependent variable has a quadratic polynomial function as follows:

$$
\mathrm{Y}_{\mathrm{k}}=\mathrm{B}_{0}+\sum_{\mathrm{j}=1}^{4} \mathrm{~B}_{\mathrm{j}} \mathrm{X}_{\mathrm{j}}+\sum_{\mathrm{i}, \mathrm{j}=1}^{4} \mathrm{~B}_{\mathrm{ij}} \mathrm{X}_{\mathrm{j}}+\sum_{\mathrm{j}=1}^{4} \mathrm{~B}_{\mathrm{jj}} \mathrm{X}_{\mathrm{j}}^{2}
$$

Yk: Dependent variable $(\mathrm{k}=1-4)$

$\mathrm{Xi}, \mathrm{j}$ : The encoding factor of the independent variable affects $\mathrm{Yk}$

$\mathrm{B}_{0}$ : Regression coefficient of 0 degree

$\mathrm{B}_{\mathrm{j}}$ : Regression coefficient of 1 degree affects the variable $X_{i}$ to $Y_{k}$

$B_{i j}$ : Coefficients of simultaneous influence of variable $\mathrm{X}_{\mathrm{j}}$ to $\mathrm{Y}_{\mathrm{k}}$

$B_{\mathrm{ij}}$ : Regression coefficient of degree 2 describes the effect of variable $\mathrm{X}_{\mathrm{j}}^{2}$ on $\mathrm{Y}_{\mathrm{k}}$ 
Table 1. Experimental design-matrix encoding the independent variables

\begin{tabular}{lcccccc}
\hline Variable name & \multicolumn{7}{c}{ Levels of evidence } \\
\hline Uncoded variable & Code variable & $-\alpha$ & -1 & 0 & +1 & $+\alpha$ \\
A: Irradiation time [min] & $\mathrm{U}_{1}$ & 1 & 2 & 3 & 4 & 5 \\
B: Extraction temperature $\left[{ }^{\circ} \mathrm{C}\right]$ & $\mathrm{U}_{2}$ & 40 & 50 & 60 & 70 & 80 \\
C: Solvent:feed ratio [mL:g] & $\mathrm{U}_{4}$ & 5 & 8 & 11 & 14 & 17 \\
D: Ethanol concentration [\%] & $\mathrm{U}_{4}$ & 30 & 40 & 50 & 60 & 70 \\
\hline
\end{tabular}

$\alpha=2, \mathrm{U}_{\min }, \mathrm{U}_{\max }$ is the lower bound $(-1)$ and upper bound $(+1)$ of the independent variable, $\mathrm{U} 0=\left(\mathrm{U}_{\min }+\mathrm{U}_{\max }\right) / 2$ is the mean value of the upper and lower bound.

\subsection{Antifungal activity screening test}

\subsubsection{Media preparation}

Potato glucose agar (PGA) medium containing $20 \mathrm{~g}$ D-Glucose, $20 \mathrm{~g}$ Agar, $200 \mathrm{~g}$ potato and $1000 \mathrm{~mL}$ distilled water were prepared. After sterilization and addition of streptomycin $(0.1 \%)$, the medium was poured in a petri dish.

\subsubsection{Fungal preparation}

Three fungal strains including P. capsisi, $F$. oxyporum and $C$. siamense were inoculated on PGA medium with antibiotic supplementation at a temperature of $25^{\circ} \mathrm{C} \pm 1$, monitored for $5-7$ days until fungal filaments overgrown agar plates.

\subsubsection{Transplantation and Mycelial growth}

Fungal plates were prepared using a disc of 9 $\mathrm{mm}$ diameter carrying mold spores on the surface of a petri dish containing highly enriched PGA medium of different concentration of $C$. odorata $(0.1 \%, 0.2 \%, 0.3 \%, 0.4 \%, 0,5 \% \mathrm{v} / \mathrm{v})$. The plates after inoculation were incubated at $25^{\circ} \mathrm{C} \pm 1$. Mycelium growth was observed and evaluated until the mycelium had grown to the plate of the non-enriched medium by measuring the mean of the two perpendicular diameters passing between the plates. Antifungal activity was evaluated by the formula (Chang et al., 2000):

$$
\mathrm{I}=\left(1-\frac{\mathrm{d}}{\mathrm{dc}}\right) \times 100
$$

where I: antifungal index, d: diameter of petri dish treated with the extracts, dc: diameter growth of the control.

\subsubsection{Data analysis}

Data was analysis of variance (ANOVA). These values are expressed as the mean \pm standard de- viation of a triplicate measurement.

\section{Results and Discussion}

\subsection{Phytochemical of $C$. odorata leaves ex- tract}

The results obtained from phytochemical screening show that alkaloid, flavonoid, tannin, phenol and saponin were detected in all the extracts irrespective of the solvent. (Table 2). Generally, ethanol extraction has better efficiency than water extraction. Due to ethanol is considered a universal solvent, as its molecular structure allows for the dissolving of both polar and nonpolar compounds (Mark, 2018).

Table 2. Active ingredients tested in extracts of $C$. odorata

\begin{tabular}{lcc}
\hline Active agents & Water extract & $\begin{array}{c}\text { Ethanol } \\
\text { extract }\end{array}$ \\
\hline Alkaloids & + & ++ \\
Flavonoids & + & ++ \\
Phenolics & + & ++ \\
Tannins & + & ++ \\
Saponins & ++ & + \\
\hline
\end{tabular}

++ moderately detected; + Detected but weak.

\subsection{Effect of extraction conditions on phenolic compounds}

The MAE process parameters were optimized to maximize TPC from $C$. odorata leaves (Table 3). In addition, the impact of each MAE parameter and their interactions were examined. The effects of extraction factors on the TPC were presented in the following function:

$\mathrm{Y}_{\mathrm{TPC}}=-490.265+43.762 \mathrm{~A}+7.284 \mathrm{~B}+$ $20.046 \mathrm{C}+5.099 \mathrm{D}+0.117 \mathrm{BC}-5.715 \mathrm{~A}^{2}-0.069 \mathrm{~B}^{2}$ $-0.932 \mathrm{C}^{2}-0.049 \mathrm{D}^{2}$

Table 4 shows the analysis of variance 
Table 3. Experimental results of total phenolic compounds (TPC)

\begin{tabular}{|c|c|c|c|c|c|}
\hline \multirow{2}{*}{ No. } & \multicolumn{4}{|c|}{ Microwave-assisted extraction variables } & \multirow{2}{*}{ TPC [mgGAE/g } \\
\hline & $\begin{array}{l}\text { A: Irradiation } \\
\text { time [min] }\end{array}$ & $\begin{array}{c}\text { B: Extraction } \\
\text { temperature } \\
{\left[{ }^{\circ} \mathrm{C}\right]}\end{array}$ & $\begin{array}{l}\text { C: Solvent:feed } \\
\text { ratio }[\mathrm{mL} / \mathrm{g}]\end{array}$ & $\begin{array}{c}\text { D: Ethanol } \\
\text { concentration } \\
{[\%]}\end{array}$ & \\
\hline 1 & 3 & 40 & 8 & 40 & 23.97 \\
\hline 2 & 5 & 40 & 8 & 40 & 36.27 \\
\hline 3 & 3 & 60 & 8 & 40 & 11.16 \\
\hline 4 & 5 & 60 & 8 & 40 & 25.2 \\
\hline 5 & 3 & 40 & 14 & 40 & 56.79 \\
\hline 6 & 5 & 40 & 14 & 40 & 62.82 \\
\hline 7 & 3 & 60 & 14 & 40 & 62.35 \\
\hline 8 & 5 & 60 & 14 & 40 & 70.74 \\
\hline 9 & 3 & 40 & 8 & 60 & 24.72 \\
\hline 10 & 5 & 40 & 8 & 60 & 38.57 \\
\hline 11 & 3 & 60 & 8 & 60 & 13.08 \\
\hline 12 & 5 & 60 & 8 & 60 & 25.17 \\
\hline 13 & 3 & 40 & 14 & 60 & 57.97 \\
\hline 14 & 5 & 40 & 14 & 60 & 63.11 \\
\hline 15 & 3 & 60 & 14 & 60 & 62.13 \\
\hline 16 & 5 & 60 & 14 & 60 & 71.10 \\
\hline 17 & 2 & 50 & 11 & 50 & 39.12 \\
\hline 18 & 6 & 50 & 11 & 50 & 59.18 \\
\hline 19 & 4 & 30 & 11 & 50 & 47.09 \\
\hline 20 & 4 & 70 & 11 & 50 & 42.05 \\
\hline 21 & 4 & 50 & 5 & 50 & 00.87 \\
\hline 22 & 4 & 50 & 17 & 50 & 78.82 \\
\hline 23 & 4 & 50 & 11 & 30 & 51.44 \\
\hline 24 & 4 & 50 & 11 & 70 & 53.47 \\
\hline 25 & 4 & 50 & 11 & 50 & 72.09 \\
\hline 26 & 4 & 50 & 11 & 50 & 71.99 \\
\hline 27 & 4 & 50 & 11 & 50 & 70.24 \\
\hline 28 & 4 & 50 & 11 & 50 & 72.24 \\
\hline 29 & 4 & 50 & 11 & 50 & 71.60 \\
\hline 30 & 4 & 50 & 11 & 50 & 70.72 \\
\hline 31 & 4 & 50 & 11 & 50 & 71.61 \\
\hline
\end{tabular}

(ANOVA) results and coefficients for TPC. The experimental data were fitted to a quadratic model. The $P$-value less than 0.05 indicated that the model was statistically significant. The irradiation time, extraction temperature, solvent to feed ratio and ethanol concentration all showed a significant effect $(P<0.05)$ on the yield of TPC. The $P$-value of the model of incompatibility test (lack to fit) is 0.087 , greater than 0.05 . Therefore, the regression model is compatible with the experiment.

The analytical results showed that four factors significantly affect the phenolic extraction process. This result was consistent with the general trend of the extraction of bioactive compounds from plant materials (Alara et al., 2019a). The results also showed that all four extraction factors including irradiation time, extraction temperature, solvent to feed ratio and ethanol concentration interacted with each other and affected the target function. Specifically, the effect of irradiation time, extraction temperature, ethanol concentration increased gradually to a critical value and if it continued to increase, it will decrease the overall value of the target function was decreased (Figure 1a, 1c, 1e). Higher quality phenolic compounds are mostly obtained from the plant matrix by using a binary solvent mixture (ethanol-water) because it depends on the polar- 
a)

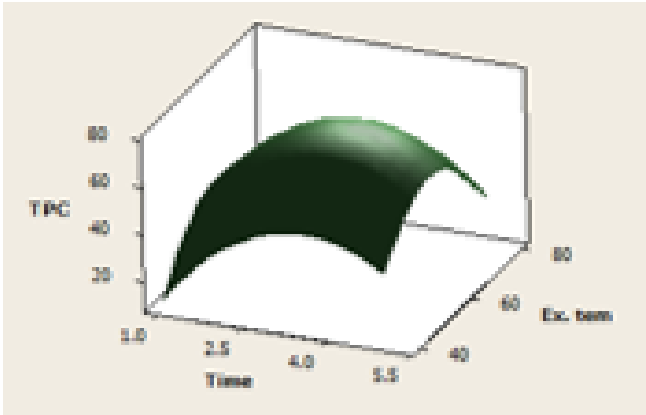

c)

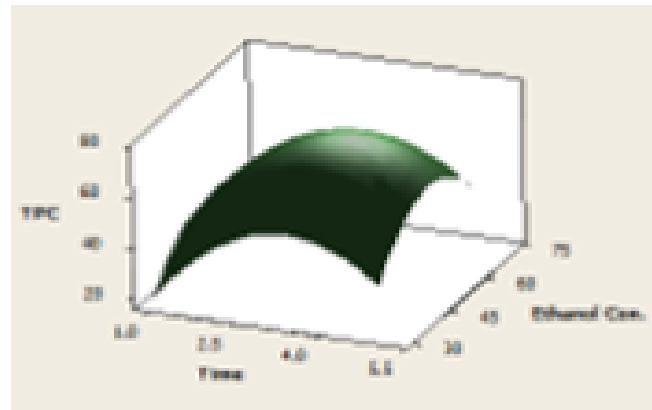

e)

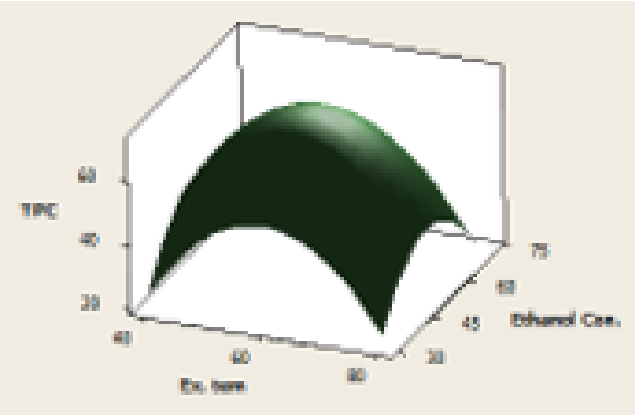

b)

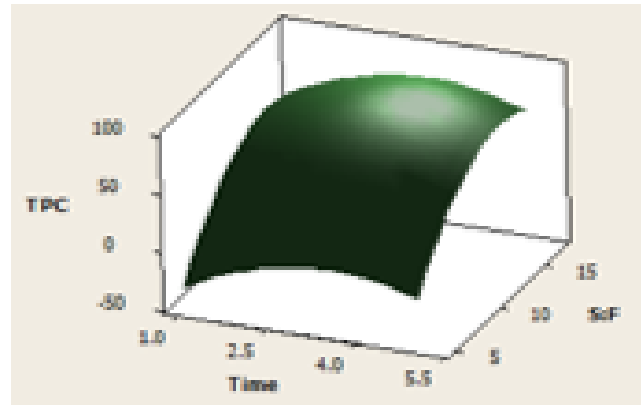

d)

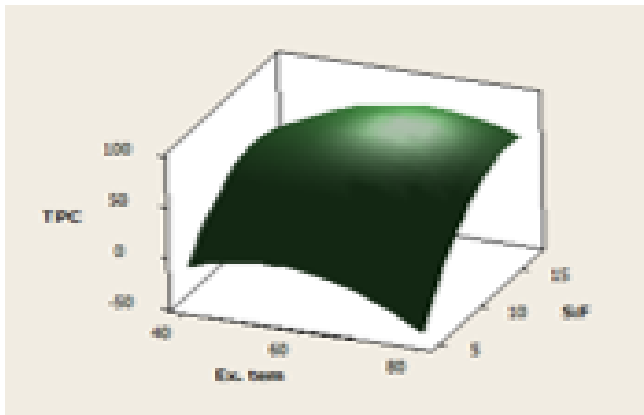

f)

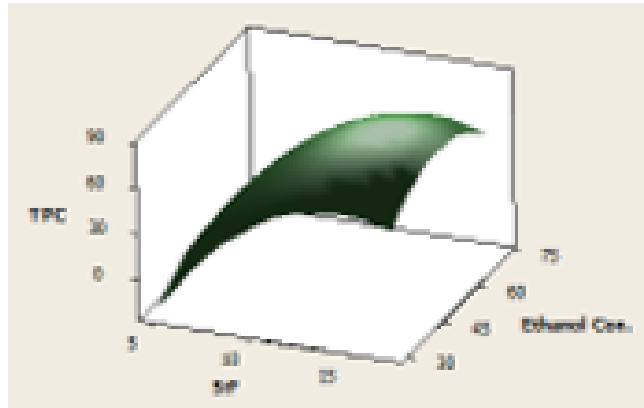

Figure 1. Response surface plots showing the influences of microwave-assisted extraction parameters on phenolic compounds. (a) irradiation time (A) versus extraction temperature (B) for total phenolic compounds (TPC); (b) A versus solvent:feed ratio (C) ; (c) A versus ethanol concentration (d) B versus C for TPC; (e) $\mathrm{B}$ versus $\mathrm{D}$ for TPC; (f) C versus D for TPC.

ity of solvents used (Alara et al., 2019a). Meanwhile, solvent to feed ratio has a positive effect on the target function (Figure 1b, 1d, 1f). Thus, from the results obtained it can be seen that within the research scope, when increasing irradiation time, extraction temperature, solvent:feed ratio, ethanol concentration to an appropriate value will increased the value of the objective function. If an increase exceeded the optimal value, it decreased the value of the target function. For solvent feed ratio when reaching the optimum value, it did not increase the value of the target function if it continued to increase. The optimized conditions of TPC might be due to the polarity of the solvent used in extraction. A previous report showed that ethanol and water were environmentally friendly solvents that could extract a higher quantity of phenolic compounds 
Table 4. Effects of the extraction factors on the target function by analysis of variance

\begin{tabular}{lccc}
\hline \multirow{2}{*}{ Variable } & \multirow{2}{*}{ df } & \multicolumn{3}{c}{ TPC [ mgGAEgDW $\left.{ }^{-1}\right]$} \\
\cline { 4 - 4 } & & F value & $P$-value probability $>$ F \\
\hline Model & 14 & 894.28 & 0.000 \\
Linear & & & \\
Irradiation time (A) & 1 & 18.80 & 0.000 \\
Extraction temperature (B) & 1 & 619.34 & 0.000 \\
Solvent:feed ratio (C) & 1 & 539.18 & 0.000 \\
Ethanol concentration (D) & & & 0.000 \\
Interation & 1 & 9.05 & 0.008 \\
$\quad \mathrm{AB}$ & 1 & 1.56 & 0.230 \\
$\mathrm{AC}$ & 1 & 0.83 & 0.375 \\
$\mathrm{AD}$ & 1 & 183.76 & 0.000 \\
$\mathrm{BC}$ & 1 & 2.85 & 0.111 \\
$\mathrm{BD}$ & 1 & 0.08 & 0.785 \\
$\mathrm{CD}$ & & & \\
Quadratic & 1 & 876.83 & 0.000 \\
$\quad \mathrm{~A}^{2}$ & 1 & 1263.56 & 0.000 \\
$\mathrm{~B}^{2}$ & 1 & 1887.42 & 0.000 \\
$\mathrm{C}^{2}$ & 1 & 641.62 & 0.000 \\
$\mathrm{D}^{2}$ & & 3.14 & 0.087 \\
Lack to fit $_{\mathrm{R}}^{2}$ & & $99.87 \%$ & \\
Adjust $\mathrm{R}^{2}$ & & $99.76 \%$ & \\
Predicted $\mathrm{R}^{2}$ & & $99.35 \%$ & \\
\hline
\end{tabular}

from the plant matrix. In a similar study, Alara et al. (2019b) obtained a TPC of $88.52 \mathrm{mgGAE} / \mathrm{g}$ from $C$. odorata leaves under MAE optimized conditions of $51 \%(\mathrm{v} / \mathrm{v})$ ethanol concentration, irradiation time of $3 \mathrm{~min}$, temperature of $60^{\circ} \mathrm{C}$ and solvent-to-material ratio of 10:1 (mL/g).

In addition, the predictive models were verified by comparing the predicted and experimental data. The predicted conditions were highest at $62^{\circ} \mathrm{C}$ for 3 min with solvent to feed ratio of $14: 1$ $(\mathrm{mL} / \mathrm{g})$ and ethanol concentration of $50 \%(\mathrm{v} / \mathrm{v})$. The results showed that the experimental values for TPC (75.76 mgGAE/g) did not vary significantly at the $5 \%$ level by using a paired t-test. Therefore, the regression equations derived from this study can be employed to optimize the extraction of phenolic compounds from $C$. odorata leaves.

\subsection{Evaluate the antifungal ability of $C$. odor- ata extract}

Total phenolic compounds of $C$. odorata leaves were extracted at optimum conditions then were evaporated to remove ethanol and prepared at 5 different concentrations, for evaluation of the an- tifungal activity against $P$. capsici, F. oxysporum and C. siamense (Table 5).

Antifungal effects increased with the increasing concentration of $C$. odorata extract from 0.1 to $0.5 \%$. Maximum antifungal effects against P. capsici was found to be $79.65 \%$ in $0.5 \%$ ethanol extract clearly (Figure 2). For F. oxysporum, the ability to inhibit fungi at concentrations of $0.1 \%, 0.2 \%$ and $0.3 \%$ was not statistically significant between treatments, but at concentrations of $0.4 \%$ and $0.5 \%$ differed significantly between treatments (Figure 3 ). Similarly, C. siamense's antifungal effect of the extracts was varying such as: (Table 4) $0 ; 41.67$; $49.67 ; 56.67 ; 63.83 ; 65.76 \mathrm{~mm}$ at $0 \%, 0.1 \%$, $0.2 \%, 0.3 \%, 0.4 \%$ and $0.5 \%$ respectively. Results showed that at all concentrations was a statistically significant difference (Figure 4). The interaction of polyphenols with nonspecific forces such as hydrogen bonding and hydrophobic effects, lipophilic forces, as well as by covalent bond formation, was related to microbial membranes, adhesions, enzymes, and cell envelope transport proteins (Cowan 1999; Kumar \& Pandey 2013). The antibacterial activity of polyphenols may be 
Table 5. Antifungal index (\%) of C. odorata extract

\begin{tabular}{cccc}
\hline \multirow{2}{*}{ Concentration $(\% \mathrm{v} / \mathrm{v})$} & \multicolumn{3}{c}{ Antifungal index $(\%)$} \\
\cline { 2 - 4 } & $P$. capsici (3 days) & F. oxysporum (5 days) & C. siamense (5 days) \\
\hline $\mathrm{NC}$ & $00.00^{\mathrm{e}}$ & $00.00^{\mathrm{d}}$ & $00.00^{\mathrm{f}}$ \\
$0.1 \%$ & $61.63^{\mathrm{d}}$ & $58.23^{\mathrm{c}}$ & $53.33^{\mathrm{e}}$ \\
$0.2 \%$ & $69.19^{\mathrm{c}}$ & $58.23^{\mathrm{c}}$ & $61.75^{\mathrm{d}}$ \\
$0.3 \%$ & $75.58^{\mathrm{b}}$ & $58.54^{\mathrm{d}}$ & $69.12^{\mathrm{c}}$ \\
$0.4 \%$ & $79.07^{\mathrm{a}}$ & $68.90^{\mathrm{b}}$ & $76.67^{\mathrm{b}}$ \\
$0.5 \%$ & $79.65^{\mathrm{a}}$ & $78.66^{\mathrm{a}}$ & $78.42^{\mathrm{a}}$ \\
\hline
\end{tabular}

In the same column, there is a statistically significant difference in values with different characters with $P<0.05$. The percentage is converted by the formula $\mathrm{y}=\sqrt{(x+0.5)}$ before analysis ANOVA.
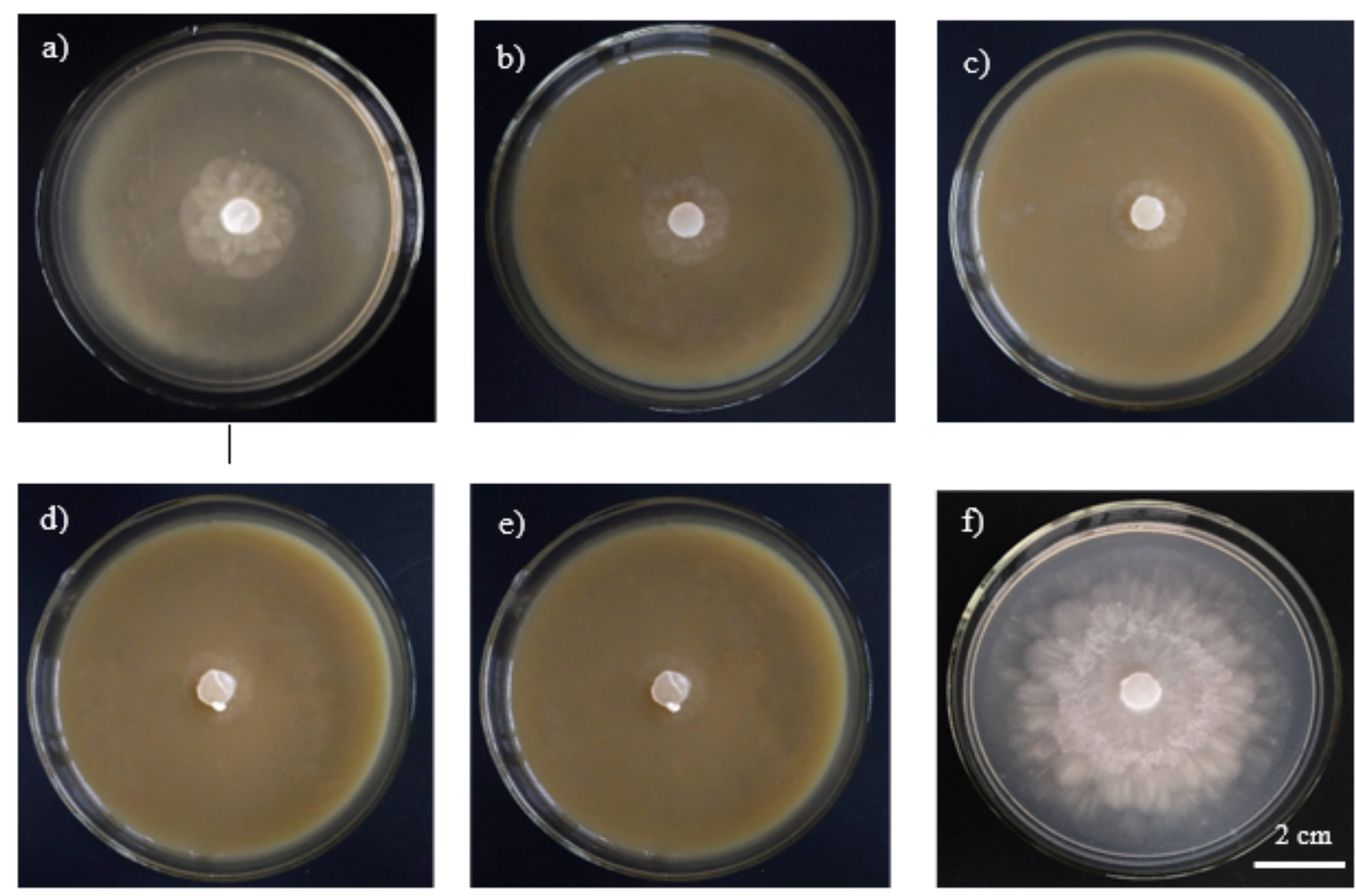

Figure 2. The antifungal ability of $C$. odorata extract against $P$. capsici at different concentration (a) $0.1 \%$ $\mathrm{v} / \mathrm{v}$; (b) $0.2 \% \mathrm{v} / \mathrm{v}$; (c) $0.3 \%$; (d) $0.4 \% \mathrm{v} / \mathrm{v}$; (e) $0.5 \% \mathrm{v} / \mathrm{v}$; (f) Negative Control (NC).

also due to the capacity of these compounds to chelate iron, vital for the survival of almost all bacteria (Field \& Lettinga, 1992). Borges et al. (2013) reported that gallic and ferulic acids induce irreversible changes in E. coli, P. aeruginosa, $S$. aureus, and L. monocytogenes membrane properties. Ting (2013) investigated the antibacterial activity and membrane interaction of 5 flavonoids (kaempferol, quercetin, chrysin, luteolin, baicalein), 2 polymethoxyflavones (tangeritin, 5,6,7,4'-tetramethoxyflavone), and 4 isoflavonoids (daidzein, genistin, ononin, puerarin) against E. coli and found that the an- tibacterial activity decreased in the following order: flavonoids $>$ polymethoxyflavones $>$ isoflavonoids. They also found that flavonoids rigidified the liposomal membrane, while the other compounds increased membrane fluidity. They suggested that the interaction of gallic and ferulic acids with bacterial cytoplasmic membranes causes hydrophobic changes, a decrease in negative surface charge, and local rupture and pore formation with leakage of intracellular constituents. The studies in the last decade have shown that phenolics with an $\mathrm{OH}$ group at the position 3 in the C-ring decrease the mem- 

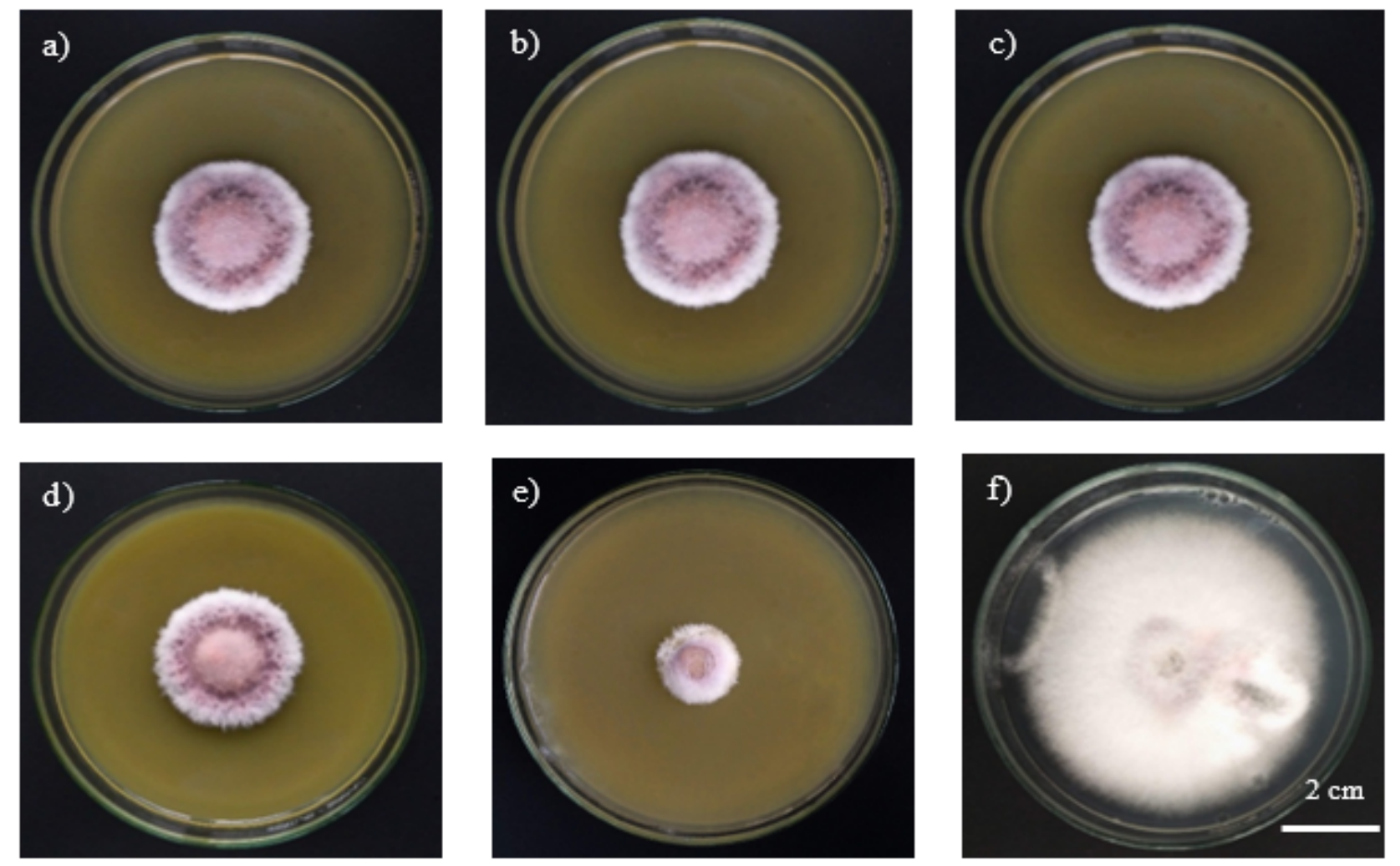

Figure 3. The antifungal ability of $C$. odorata extract against $F$. oxysporum at different concentration (a) $0.1 \% \mathrm{v} / \mathrm{v}$; (b) $0.2 \% \mathrm{v} / \mathrm{v}$; (c) $0.3 \%$; (d) $0.4 \% \mathrm{v} / \mathrm{v}$; (e) $0.5 \% \mathrm{v} / \mathrm{v}$; (f) Negative Control.
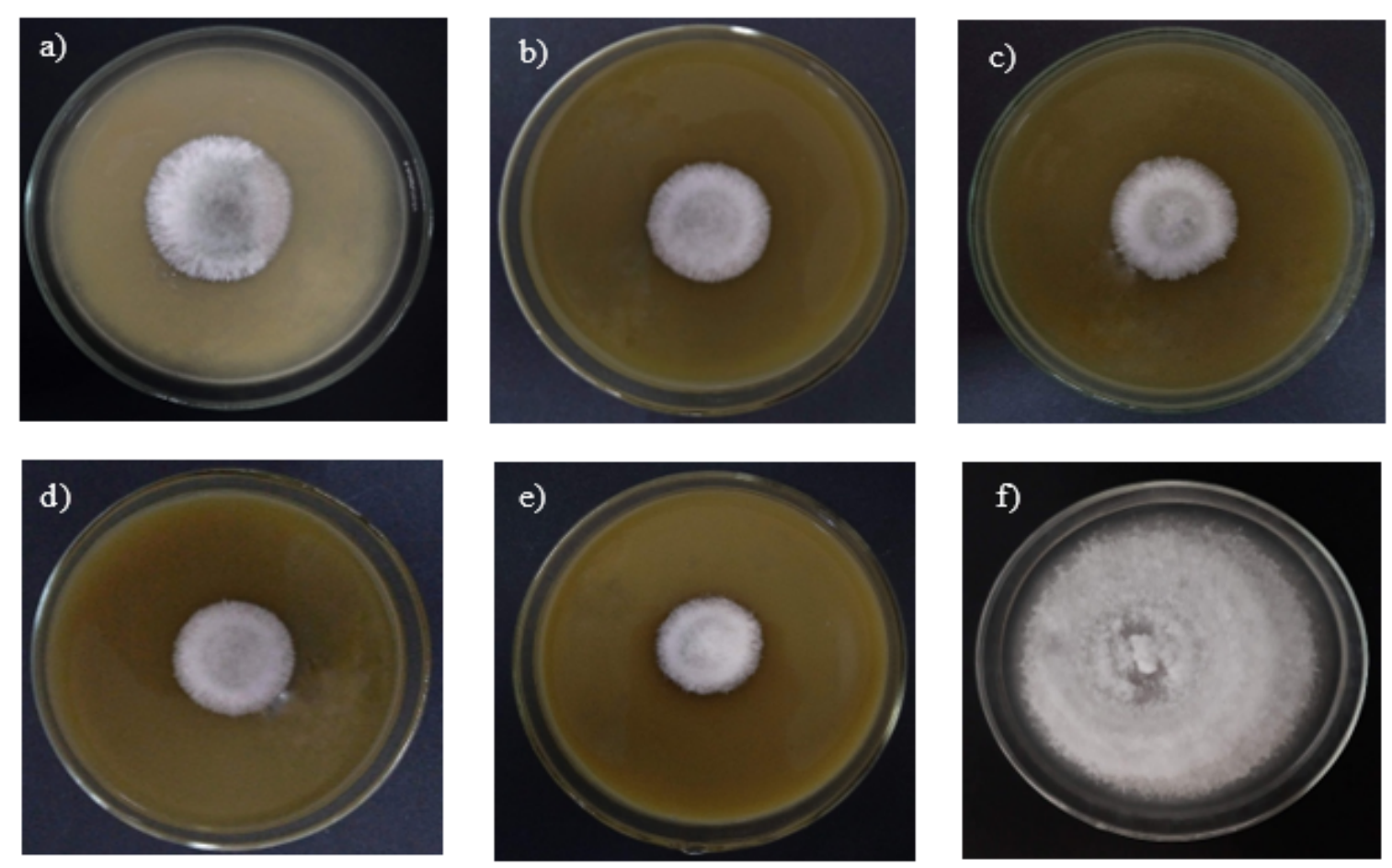

Figure 4. The antifungal ability of $C$. odorata extract against $C$. sianmense at different concentration (a) $0.1 \% \mathrm{v} / \mathrm{v}$; (b) $0.2 \% \mathrm{v} / \mathrm{v}$; (c) $0.3 \%$; (d) $0.4 \% \mathrm{v} / \mathrm{v}$; (e) $0.5 \% \mathrm{v} / \mathrm{v}$; (f) Negative Control. 
brane fluidity leading to membrane rigidification (Tsuchiya, 2010; Ting, 2013). Many studies have used membrane models to elucidate the interaction of polyphenols with the phospholipids of the bilayer lipid membrane. In addition, $F$. oxysporum YT1 and PT1 were cultured in vitro in the presence of $C$. odorata leaf extract. Mycelium growth was reduced at concentrations of 20,30 and $40 \mathrm{~g} / \mathrm{L}$ but stopped at $50 \mathrm{~g} / \mathrm{L}$. (Kra, 2009). The above was resulted contribute to affirm that $C$. odorata leaves extract has good antifungal ability as reported by Adeyemo (2018) using $C$. odorata extract by maceration to inhibit $P$. megakarya from $15.00 \mathrm{~mm}$ to $32.00 \mathrm{~mm}$ at concentrations of $1 \%$ and $5 \%$ respectively for positive control $41.00 \mathrm{~mm}$.

\section{Conclusions}

Optimal total phenolic compounds TPC of $C$. odorata leaves was $75.76 \mathrm{mgGAE} / \mathrm{g}$ at $62^{\circ} \mathrm{C}$ for 3 min with solvent to feed ratio of $14: 1(\mathrm{~mL} / \mathrm{g})$ and ethanol concentration of $50 \%(\mathrm{v} / \mathrm{v})$. Ethanol extract clearly showed antifungal activity through antifungal index. The highest antifungal effect on $P$. capsici, F. oxysporum and C. siamense were $79.65 \%, 78.66 \%$ and $78.42 \%$ in $0.5 \%$ of ethanol extract, respectively. The findings demonstrated the potential of using $C$. odorata leaf extract as a source of biopesticide production, not only the environment but also the ecosystem and biodiversity.

\section{Acknowledgement}

The authors acknowledge support from the Research Institute for Biotechnology and Environment, Nong Lam University, Ho Chi Minh City.

\section{Conflict of interest declaration}

The authors have declared no conflict of interest.

\section{References}

Alara O. R., Abdurahman N. H., \& Mudalip, S. K. A. (2019a). Optimizing microwave-assisted extraction conditions to obtain phenolic-rich extract from Chromolaena odorata leaves. Chemical Engineering Technology 42, 1733-1740.

Alara O. R., Abdurahman N. H., \& Mudalip, S. K. A. (2019b). Screening of microwave-assisted-batch extraction parameters for recovering total phenolic and flavonoid contents from Chromolaena odorata leaves through two-Level factorial design. Indonesian Journal of Chemistry 19, 511-521.

Adeyemo, I. A., Omotunlese, I. V., \& Oni, M. O. (2018). Phytochemical screening and antifungal activity of Chromolaena odorata extracts against isolate of Phytophthora megakarya using agar-well diffusion method. Asian Journal of Medical and Biological Research $4(1), 7-13$.

Borges, A., Ferreira, C., Saavedra, M. J., \& Simoes, M. (2013). Antibacterial activity and mode of action of ferulic and gallic acids against pathogenic bacteria. $\mathrm{Mi}$ crobial Drug Resistance 19,256-265.

Chang, S. T., Wang, S. Y., Wu, C. L, Chen, P. F., \& Kuo, Y. H. (2000). Comparison of the antifungal activity of cadinane skeletal sesquiterpenoids from Taiwania (Taiwania cryptomerioides Hayata) heartwood. Holzforschung 54, 241-245.

Cowan, M. M. (1999). Plant products as antimicrobial agents. Clinical Microbiology Reviews 12, 564-582.

Dwijendra, S. (2014). Advances in Plant Biopesticides. New Delhi, India: Springer.

Field, J. A., \& Lettinga, G. (1992). Toxicity of tannic compounds to microorganisms. In: Hemingway, R. W., and Laks, P. E. (Eds.). Plant polyphenols, synthesis, properties, significance (673-692). New York, USA: Plenum Press.

Khuri, A. I., \& Mukhopadhyay, S. (2010). Response surface methodology. Wiley Interdisciplinary Reviews Computational Statistics 2(2), 128-149.

Kra, K. D., Diallo, H. A., \& Kouadio, Y. J. (2009). Antifungal activity of Chromolaena odorata (L.) King \& Robins extract on two isolates of Fusarium oxysporum (E. F. Sm.) responsible for lethal yellowing of the leaves of banana trees. Journal of Applied Biosciences $24,1488-1496$.

Kumar, S., \& Pandey, A. K. (2013). Chemistry and biological activities of flavonoids: An overview. The Scientific World Journal 2013, 1-16. https://doi.org/10.1155/2013/162750.

Kumar, Y., Yadav, D. N., Ahmad, T., \& Narsaiah, K. (2015). Recent trends in the use of natural antioxidants for meat and meat products. Comprehensive Reviews in Food Science and Food Safety 14,796-812.

Kumlachew, A., Amare, A., \& Kebede, W. (2014). Antifungal activity of plant extracts and their applicability in extending the shelf life of mango fruits. Food Science and Quality Management 33, 47-53.

Mark, J. W. (2018). Your guide to ethanol extraction in Cannabis. Cannabis Business Times.

Moses, S. O., Akintayo, O., Kamil, O. Y., Labunmi, L., Heather, E. V., Jessika, A. T., \& William, N. S. (2010). Chemical composition and bioactivity of the essential oil of Chromolaena odorata from Nigeria. Records of Natural Products 4(1), 72-78. 
Ting, W., Xixi, Z., Mengying, H., Siyi, P., \& Xiaoyun, X. (2013). Structure-activity relationship of flavonoids on their anti-Escherichia coli activity and inhibition of DNA gyrase. Journal of Agricultural and Food Chemistry 61, 8185-8190.
Tsuchiya, H. (2010). Structure-dependent membrane interaction of flavonoids associated with their bioactivity. Food Chemistry 120(4), 1089-1096. 